\title{
PENINGKATAN KESEJAHTERAAN IBU HAMIL DENGAN PRENATAL GENTLE YOGA DAN RELAKSASI DI KELURAHAN GUNUNG LINGKAS TARAKAN
}

\author{
Ririn Ariyanti ${ }^{1}$, Doris Noviani ${ }^{1}$, , Ika Yulianti ${ }^{1}$, Gusriani ${ }^{11}$ \\ 1)S1 Kebidanan, Fakultas IImu Kesehatan, Universitas Borneo Tarakan, Tarakan, Kalimantan Utara, Indonesia \\ Corresponding author :Ririn Ariyanti \\ E-mail : ririn_ariyanti@borneo.ac.id
}

Diterima 25 November 2021, Direvisi 04 November 2021, Disetujui 04 November 2021

\begin{abstract}
ABSTRAK
Selama kehamilan pikiran dan tubuh ibu hamil mengalami berbagai perubahan. Perubahan fisik yang muncul mengakibatkan ibu mengalami beberapa keluhan nyeri pada punggung bagian belakang, badan terasa lebih lemas, dan mudah lelah. Prenatal gentle yoga dan relaksasi dapat dilakukan selama kehamilan dapat membantu meningkatkan kesejahteraan ibu. Berdasarkan wawancara dengan kader kesehatan di Wilayah kelurahan Gunung Lingkas Tarakan ibu hamil sering mengeluhkan badan terasa pegal - pegal, nyeri punggung dan kaku, selain itu ibu hamil di wilayah ini belum pernah mengikuti senam selama hamil. Kegiatan ini berlangsung di kelurahan Gunung Lingkas Tarakan. Latihan prenatal gentle yoga dan relaksasi dapat mengurangi keluhan keluhan yang muncul pada kehamilan, serta dapat membantu membuat ibu lebih tenang dan rileks selama kehamilan, serta membantu mempersiapkan ibu dalam menghadapi persalinanya menjadi lebih tenang, mudah dan lancar.
\end{abstract}

Kata kunci: prenatal gentle yoga; rileksasi.

\begin{abstract}
During pregnancy, the mind and body of a pregnant woman undergo various changes. The physical changes that appear cause the mother to experience several complaints of pain in the back, the body feels weaker, and gets tired easily. Prenatal gentle yoga and relaxation can be done during pregnancy can help improve the well-being of the mother. Based on interviews with health cadres in the Gunung Lingkas sub-district, Tarakan, pregnant women often complain of body aches, back pain and stiffness, besides that pregnant women in this area have never participated in exercise during pregnancy. This activity took place in the village of Gunung Lingkas, Tarakan. Gentle yoga and relaxation prenatal exercises can reduce complaints that arise in pregnancy, and can help make mothers calmer and more relaxed during pregnancy, and help prepare mothers to face childbirth to be calmer, easier and smoother.
\end{abstract}

Keywords: prenatal gentle yoga; relaxation

\section{PENDAHULUAN}

Angka Kematian Ibu (AKI) merupakan salah satu indikator untuk melihat keberhasilan upaya kesehatan ibu. AKI adalah rasio kematian selama masa kehamilan, persalinan dan nifas yang disebabkan oleh kehamilan, persalinan dan nifas atau pengelolaannya tetapi bukan karena sebab sebab lain seperti kecelakaan atau terjatuh di setiap 100.000 kelahiran hidup. Selain itu menilai program kesehatan ibu, indicator ini juga mampu menilai derajat kesehatan masyarakat, karena sensitifitasnya. Penilaian terhadappelaksanaan terhadap perbaikan pelayanan kesehatan, baik dari segi aksesbilitas maupun kualitas. Secara umum terjadi penurunan kematian ibu selama periode 1991-2015 dari 390 menjadi 305 per 100.000 kelahiran hidup. Walaupun terjadi kecenderungan menurun pada AKI,namun tidak berhasil mencapai target MDGs yang harus dicapai sebesar 102 per 100.000 kelahiran hidup pada tahun 2015 (Kemenkes RI, 2019).

Upaya percapaian target MDGs di bidang kesehatan, yaitu penyelenggaraan upaya kesehatan ditingkatkan intensitasnya dengan tetap memberikan perhatian khusus pada penyelenggaraan pelayanan Kesehatan Ibu dan Anak (KIA). KIA dilakukan selama kehamilan diawali konsepsi hingga usia kehamilan mencapai 40 minggu. Selama proses tersebut, ibu mengalami perubahan fisiologis, psikologis dan social (Hamidiyanti \& Pratiwi, 2020).

Wanita hamil mengalami banyak perubahan, baik itu perubahan secara fisik maupun perubahan secara psikologis yang dapat menimbulkan ketidaknyamanan terutama trimester III seperti dispnea, insomnia, gingiviris dan epulsi, sering buang air kecil, (Retnowati et 
al., 2019). Tekanan dan ketidaknyamanan pada perineum, nyeri punggung, konstipasi, varises, mudah lelah, kontraksi Braxton hicks, kram kaki, edema pergelangan kaki (non pitting) dan perubahan mood serta peningkatan kecemasan (Febyanti \& Susilawati, 2012).

Perubahan psikologis pada wanita hamil menurut Hamilton (2015), dapat dilihat dari pemeriksaan fisik dan psikologisnya. Ibu hamil dalam masa kehamilannya menimbulkan reaksi yang berbeda dalam menghadapinya, hal itu tergantung dari sifat masing-masing individu yang berdasarkan pengalaman, pendidikan dan tingkat kedewasaan meskipun sebagian besar wanita dalam menghadapi kehamilan merasakan ketakutan, kecemasan yang disebabkan oleh banyak faktor terutama pada ibu primigravida (Chen et al., 2017).

Yoga merupakan bentuk pengobatan fisik dan sprititual yang sudah digunakan selama 5000 tahun yang lalu. Yoga berasal dari bahasa Sansekerta "yug" yang berarti "penyatuan" dan bermakna "penyatuan dengan alam" atau " penyatuan dengan sang pencipta". Teknik yang digunakan pada saat yoga membawa keseimbangan pada aspek tubuh, pikiran, dan kepribadian yang berbeda sehingga penggunaannya penuh dengan energi, kekuatan dan kejelasan tujuan hidup (Aprilia, 2020). Yoga merupakan suatu teknik latihan untuk mengenal diri sehingga dapat menganalisis lebih lanjut tentang pikiran dan tindakan yang sudah dilakukan. Latihan dilakukan melalui sikap tubuh (asana), dan pernafasan (pranayama), dan teknik relaksasi sehingga dapat mengembangkan kecerdasan intuisi alamiah dan membantu pikiran agar dapat terpusat, dan pada akhirnya dapat membuat perubahan berupa ketenangan pikiran, dan terpusatnya perhatian. Yoga mencakup aspek postur tubuh (asana), teknik pernafasan (pranayama), meditasi (dhyana), nyayian (mantra) dan ajaran kebijaksanaan (sutra) untuk mendorong kesehatan dan relaksasi. Sebuah tinjauan sistematis yoga efektif untuk mengurangi kecemasan, depresi, dan rasa sakit akut maupun kronis pada populasi dewasa tanpa efek samping. Intervensi yoga meningkatkan kesehatan psikologis (kecemasan, depresi, tertekan, stres) dan dapat meningkatkan kualitas hidup (Rusmita, 2015).

Senam yoga merupakan sebuah rangsangan relaksasi yang terorganisir yang terdiri dari melodi, ritme, harmoni, timbre, latihan pernafasan, relaksasi dan meditasi. Senam yoga memiliki kekuatan untuk mengobati penyakit dan ketidakmampuan yang dialami oleh setiap orang (Veronica et al., 2020). Ketika senam yoga diaplikasikan menjadi sebuah terapi, dapat meningkatkan, memulihkan dan memelihara kesehatan fisik, mental, emosional, sosial dan spiritual dari setiap individu (Ariyanti \& Jalilah, 2021). Hal ini dikarenakan, senam yoga memiliki beberapa kelebihan, seperti senam yoga bersifat universal, nyaman, menyenangkan dan berstruktur. Perlu diingat bahwa banyak dari proses dalam hidup kita berakar dari irama. Sebagai contoh, nafas kita, detak jantung dan pulsasi semuanya berulang dan berirama (Mayasari \& Mustikasari, 2021).

Latihan prenatal gentle yoga dan relaksasi dapat mengurangi keluhan keluhan yang muncul pada kehamilan, serta dapat membantu membuat ibu lebih tenang dan rileks selama kehamilan, serta membantu mempersiapkan ibu dalam menghadapi persalinanya menjadi lebih tenang, mudah dan lancar (Aprilia, 2020).

\section{METODE}

Metode pelaksanaan dalam kegiatan ini dilakukan dalam empat tahapan yakni tahap perencanaan, tahap pelaksanaan, tahap monitoring dan tahap evaluasi. Pada tahap perencanaan yakni mengajukan permohonan ijin dengan kantor Kelurahan Gunung Lingkas, Tarakan serta berkoordinasi dengan kader kesehatan di wilayah kerja kelurahan Gunung Lingkas, mendata ibu hamil yang ada di wilayah tersebut serta mempersiapkan tempat dan waktu kegiatan. Tahap kedua adalah pelaksanaan kegiatan pengabdian masyarakat yang di laksanakan di Aula Kelurahan Gunung Lingkas Tarakan, kegiatan ini di awali dengan penyuluhan tentang adaptasi atau perubahan perubahan yang terjadi selama kehamilan, kemudian dilakukan edukasi prenatal gentle yoga, dan dilanjutkan dengan praktek prenatal gentle yoga bagi ibu hamil dan relaksasi pada kehamilan.

Tahap monitoring di lakukan selama pengabdian masyarakat ini dilakukan untuk melihat apakah peserta dapat mengikuti kegiatan dengan baik dan apakah dapat mengikuti arahan dari fasilitator prenatal gentle yoga serta apakah ada keluhan yang muncul selama dilakukan prenatal gentle yoga tersebut dan tahap yang terakhir adalah tahap evaluasi dimana di tahap ini digunakan untuk mengevaluasi perencanaan dan pelaksanaan dari program pengabdian masyarakat yang telah diberikan kepada ibu hamil. Evaluasi kegiatan dengan mengevaluasi keluhan ibu hamil ibu di utarakan pada saat awal pertemuan apakah mengalami perubahan setelah dilakukan prenatal gentle yoga dan testimoni dari ibu hamil yang mengikuti prental gentle yoga. Nyeri punggung belakang atau LBP 
dievaluasi menggunakan visual analog scale (VAS). Evaluasi yang dilakukan untuk melihat apakah program yang diberikan dapat mengurangi keluhan - keluhan

\section{HASIL DAN PEMBAHASAN}

Program pengabdian masyarakat ini bertujuan untuk meningkatkan kemampuan ibu hamil dalam mengurangi keluhan yang muncul selama kehamilan melalui peningkatan pemahaman tentang adaptasi yang terjadi selama kehamilan, dan aktivitas yang dapat dilakukan perempuan selama kehamilan serta peningkatan kemampuan ibu hamil dalam melakuan senam prenatal gentle yoga untuk mengurangi keluhan yang dirasakan. Hasil yang diperoleh setelah mengikuti program ini semua ibu hamil tetap memiliki kualitas hidup yang baik. Kualitas hidup merupakan persepsi ibu hamil terhadap dirinya yang berkaitan dengan fisik, psikologis, sosial dan lingkungan. Ibu hamil yang memiliki kualitas hidup baik dapat meningkatkan perannya dan meningkatkan kesejahteraan dirinya.

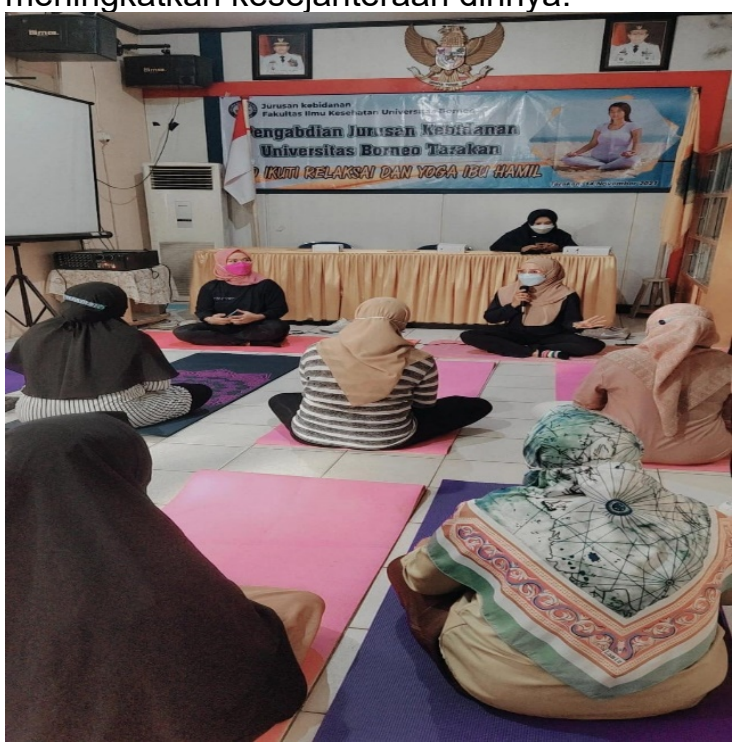

Gambar 1. Penyuluhan dan Edukasi Pra Prenatal Gentle Yoga

Setelah mengikuti prenatal gentle yoga, ibu hamil mengatakan bahwa keluhan yang sebelumnya di rasakan seperti badan pegal pegal, sering kesemutan, dan nyeri pada bagian punggung berkurang dan merasakan perubahan yang positif yakni badan terasa segar, ringan, kesemutan dan nyeri punggung berkurang. Prenatal gentle yoga yang dilakukan rutindapat membantu mengurangi keluhan ketidaknyamanan yang dialami oleh ibu hamil (Battle et al., 2015). Terdapat perbedaan yang signifikan antara ibu hamil yang mendapatkan prenatal gentle yoga dengan yang tidak melakukan prenatal gentle yoga hamil terhadap nyeri punggung dan disabilitas saat hamil. Senam yoga hamil yang menyatukan mind-body dapat meningkatkan kesehatan, mengurangi stress dan meningkatkan kesadaran diri bagi ibu hamil (Muzik et al., 2012)

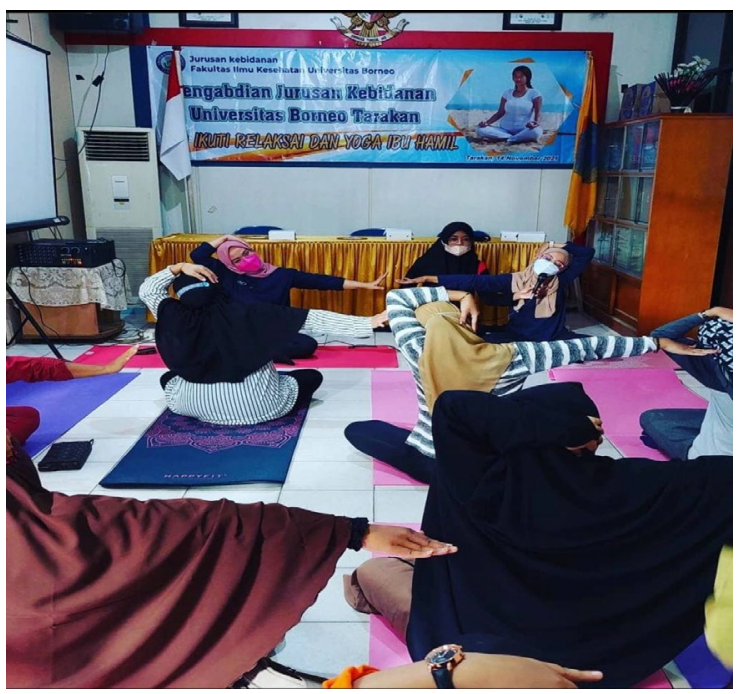

Gambar 2. Pelaksanaan Prenatal Gentle Yoga pada Ibu Hamil

Pelaksanaan pengabdian masyarakat senam yoga prenatal terdapat beberapa kesulitan seperti kesulitan saat sesi relaksasi karena terdapat suara yang mengganggu sehingga peserta tidak bisa fokus, namun kendala tersebut dapat diatasi dengan memindahkan lokasi kegiatan diruang tertutup sehingga bukan menjadi kendala yang berarti saat prenatal gentle yoga.

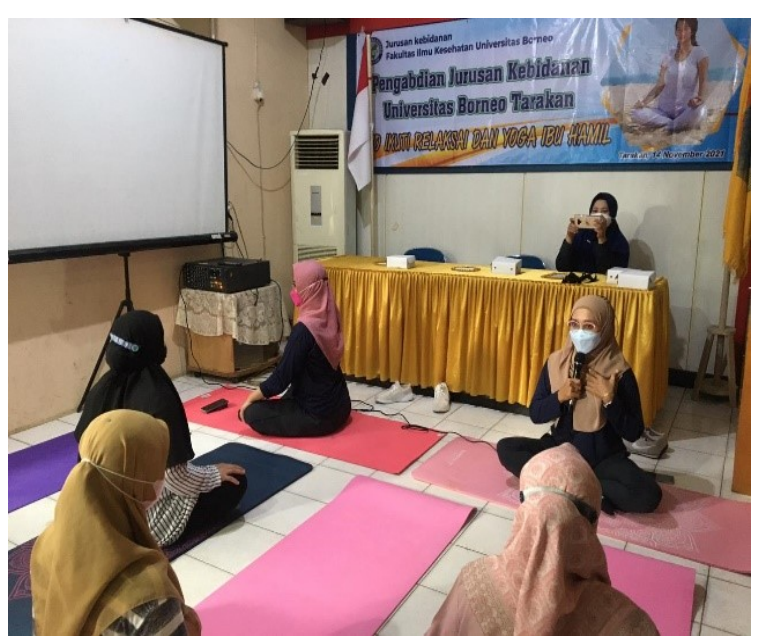

Gambar 3. Relaksasi pada Ibu Hamil

\section{SIMPULAN DAN SARAN}

Kegiatan ini mampu meningkatkan kemampuan ibu hamil dalam melakukan senam prenatal gentle yoga. Ibu hamil yang mengikuti kegiatan dapat melakukan gerakan prenatal gentle yoga yang sederhana di rumah untung mengurangi keluhan yang muncul pada 
kehamilan dan mempersiapkan diri dalam menghdapai persalinannya. Program ini baik jika dapat diterapkan pada ibu hamil secara rutin untuk mendapatkan hasil yang optimal.

\section{UCAPAN TERIMAKASIH}

Terimakasih kepada LPPM (Lembaga

Penelitian dan Pengabdian Masyarakat) Universitas Borneo Tarakan sebagai pemberi dana kegiatan pengabdian masyarakat ini dan kami ucapkan terimakasih kepada kelurahan Gunung Lingkas Tarakan dan Kader Kesehatan yang menjadi mitra dalam peningkatan kesejahteraan ibu hamil.

\section{DAFTAR RUJUKAN}

Aprilia, Y. (2020). Prenatal Gentle Yoga Kunci Melahirkan dengan Lancar, Aman, Nyaman dan Minim Trauma. PT. Gramedia Pustaka Utama.

Ariyanti, R., \& Jalilah, N. H. (2021). Kelas Ibu Hamil Pada Masa Pandemi COVID-19. JURNAL PENGABDIAN MASYARAKAT BORNEO, 5(01), 51-56.

Battle, C. L., Uebelacker, L. A., Magee, S. R., Sutton, K. A., \& Miller, I. W. (2015). Potential for Prenatal Yoga to Serve as an Intervention to Treat Depression During Pregnancy. Women's Health Issues, 25(2), 134-141. https://doi.org/10.1016/J.WHI.2014.12.00 3

Chen, P. J., Yang, L., Chou, C. C., Li, C. C., Chang, Y. C., \& Liaw, J. J. (2017). Effects of prenatal yoga on women's stress and immune function across pregnancy: A randomized controlled trial. Complementary Therapies in Medicine, 31, 109-117.

https://doi.org/10.1016/j.ctim.2017.03.003

Febyanti, N. K., \& Susilawati, D. (2012). Hubungan Pengetahuan Ibu Hamil Tentang Antenatal Care terhadap Perilaku Kunjungan Kehamilan. Soedirman Journal of Nursing, 7(3), 148-157.

Hamidiyanti, B. Y. F., \& Pratiwi, I. G. (2020). Efektifitas Prenatal Yoga Terhadap Pengurangan Keluhan Fisik Pada Ibu Hamil Trimester lii Di Kelurahan Dasan Cermen Wilayah Kerja Puskesmas Babakan Kecamatan Sandubaya. Jurnal Pengabdian Masyarakat Sasambo, 1(2), 52.

https://doi.org/10.32807/jpms.v1i2.474

Hamilton. (2015). Perawatan 40 hari pasca persalinan. Puspa Swara.

Kemenkes RI. (2019). Profil Kesehatan Indonesia 2018. Kementrian Kesehatan Republik Indonesia.

Mayasari, E., \& Mustikasari, U. (2021). PKM
YOGA PRANATAL DI DI POSYANDU MEKAR WILAYAH KERJA UPT BLUD PUSKESMAS TAPUNG HULU I. COVIT (Community Service of Health), 1(2), 2226.

Muzik, M., Hamilton, S. E., Lisa Rosenblum, K., Waxler, E., \& Hadi, Z. (2012). Mindfulness yoga during pregnancy for psychiatrically at-risk women: Preliminary results from a pilot feasibility study. Complementary Therapies in Clinical Practice, 18(4), 235240.

https://doi.org/10.1016/J.CTCP.2012.06.0 06

Retnowati, Y., Yulianti, I., \& Ariyanti, R. (2019). Pengantar Asuhan Kehamilan. CV. Bromomurup.

Rusmita, E. (2015). Pengaruh Senam Hamil Yoga Terhadap Kesiapan Ibu Hamil Menghadapi Persalinan Di RSIA Limijati Bandung [JOUR]. KEPERAWATAN, 3(2).

Veronica, P. A., Enggar, Lastri, G. H., \& Rafiah, S. (2020). The effect of prenatal yoga on the anxiety level of pregnant women. Enfermería Clínica, 30, 331-334. https://doi.org/10.1016/J.ENFCLI.2020.06 .074 